\title{
The effect of degree and type of training upon extinction of a response chain in pigeons'
}

KURT W. FISCHER

HARVARD UNIVERSITY

\begin{abstract}
Pigeons were given extensive training in a two link response chain with a variable interval (VI) schedule in each link. Some animals were given relatively massed training and small food rewards (nonsatiation training); others distributed training and large food rewards (satiation training). During extinction, animals with high training in the satiation condition differed from other animals in that they showed higher response rates in the initial link relative to the terminal link.
\end{abstract}

Lashley (1951) pointed out 16 years ago that the nature of response sequencing is one of the crucial problems for psychology, yet little work has been done on response sequence organization. "Chained" schedules of reinforcement, where reward is contingent upon performance of a response in the presence of at least two successive stimuli, provide a useful technique for investigating response sequencing. Behavior during extinction of such response chains can give valuable information about the way elements (links) of a chain hang together.

Data on behavior during extinction of response chains are contradictory. Napalkov (1959) and Reese (1964, pp. 173-176) found that, during extinction, responding decreased first in the initial links and only later in the terminal links; that is, responding was maintained longer in the portion of the sequence which was temporally closer to reinforcement. Fantino (1965), on the other hand, found the opposite result. He trained pigeons for a year or more in a two link chain. During extinction the response rate in the initial link was maintained several sessions longer than the rate in the terminal link. But a straightforward interpretation of the results was precluded because different reinforcement schedules were used in the two links. The present study was designed to determine whether the differential extinction effect would occur with a VI schedule in each link.

\section{Procedure}

Subjects were eight male white Carneaux pigeons. Each bird was food deprived until it reached either 75 or $80 \%$ of its normal free feeding body weight.

Training took place in a standard operant conditioning chamber (Ferster \& Skinner, 1957) with two response keys. At the beginning of a session the left response key was transilluminated by a green light mounted behind it, and the right key was dark. Pecking at the left key (initial link) was rewarded on a VI $45 \mathrm{sec}$ schedule by the production of a red light on the right key. At the same time the left key became dark and inoperative. Responses on the right key were then rewarded on a VI $45 \mathrm{sec}$ schedule by the presentation of food for a given number of seconds, during which both keys were dark and the lights in the reinforcement magazine were illuminated. At the end of reinforcement, the left key was again transilluminated. During extinction the procedure was identical except that the reinforcement magazine was no longer operated and the magazine lights were not illuminated.

Several different training routines were employed (Table 1). Pigeons 1 and 2 (NONSAT) were trained in sessions of 63 reinforcements of $3 \mathrm{sec}$ each. Typically, sessions lasted about $2 \mathrm{~h}$, with one session per day on consecutive days, but occasionally two sessions were included in one day. Total training covered about four months.

Pigeons 4, 5, 6, 7, and 8 were trained as part of another experiment (Fischer \& Fantino, in preparation) with a similar procedure. The one major difference was that in the other experiment the bulk of training was under "satiation" conditions; that is, the animals were allowed to eat large quantities of food during a session with reinforcement periods of 6-14 sec. As a result, delays of two to five days between sessions were required to restore the appropriate body weight. Birds 4 and 5 (SAT) were studied throughout training in virtually identical sessions of 84 reinforcements each, while Birds 6 , 7 , and 8 (VARSAT) underwent variations in several critical variables (duration of reinforcement, length of session). At the end of satiation training, all five pigeons were given 10 training sessions identical to those used for Pigeons 1 and 2.

Pigeon 3 (NONSAT*) was given extensive training in a short period of time. Over a period of three months, the bird was trained almost every day for up to $16 \mathrm{~h}$ a day. Reinforcement duration was $3 \mathrm{sec}$.

\begin{tabular}{cllccc}
$\begin{array}{c}\text { Pigeon } \\
\text { No. }\end{array}$ & Training & $\begin{array}{c}\text { Table 1. Training and Extinction } \\
\text { Body } \\
\text { Weight }\end{array}$ & $\begin{array}{c}\text { No.Rein- } \\
\text { forcement }\end{array}$ & $\begin{array}{c}\text { Sessions to } \\
\text { Extinction }\end{array}$ & $\begin{array}{c}\text { Ratio of } \\
\text { Relative Rates }\end{array}$ \\
\hline 1 & NONSAT & $80 \%$ & 4473 & 6 & 0.77 \\
2 & NONSAT & 75 & 4641 & 6 & 0.42 \\
3 & NONSAT & 75 & 23,576 & 4 & 0.72 \\
4 & SAT & 80 & 5446 & 4 & 1.47 \\
5 & SAT & 75 & 6521 & 11 & 1.43 \\
6 & VARSAT & 75 & 3600 & 8 & 1.67 \\
7 & VARSAT & 75 & 2950 & 4 & 0.08 \\
8 & VARSAT & 80 & 2300 & 3 & 0.12 \\
\hline
\end{tabular}

${ }^{a}$ NONSAT $=$ nonsatiation; NONSA $T^{*}=$ nonsatiation, intensive training; $S A T=$ satiation; $V A R S A T=$ variable satiation. 
The total number of reinforcements was 23,576 -equivalent to 374 sessions of 63 reinforcements. During the last 12 sessions before extinction, the bird received 189 reinforcements per session. The last seven reinforcement sessions and all extinction sessions were administered at one per day.

For all birds except No. 3, the extinction procedure was standard. All extinction sessions and the four sessions immediately preceding extinction occurred at one per day on consecutive days. A session was terminated when a bird had completed 63 chains or after $5 \mathrm{~h}$. The criterion for final extinction was failure to respond for $2 \mathrm{~h}$ during one of the daily sessions. The extinction procedure for Bird 3 was identical except that extinction lasted $6 \mathrm{~h}$ each day; $6 \mathrm{~h}$ was slightly more than the minimum time needed to finish 189 chains.

\section{Results}

The results were analyzed in terms of "absolute" response rate and "relative" response rate. Absolute rate is the mean number of responses per min; relative rate is the ratio of absolute rate in the initial link to the sum of the absolute rates in the two links.

Three of the present animals (Nos. 4, 5, and 6) showed a weak version of Fantino's (1965) results. These three birds all had similar training; they were the three Ss with the most training under satiation conditions. Bird 6 had much less training than Birds 4 and 5, but more than any of the other birds with variable-satiation training.

Two different statistical analyses demonstrated the reliability of the results. Birds 4,5 , and 6 each had at least one extinction session in which the absolute rate in the initial link was higher than that in the terminal link by at least one response per min. ${ }^{2}$ When the birds were dichotomized on: (a) high practice in satiation training vs other groups, and (b) presence or absence of at least one extinction session with a higher absolute rate in the initial link, the resulting 2 by 2 contingency table showed a significant relationship between the two dichotomized variables $\left(X^{2}=4.3, p<.05\right)$.

The second analysis showed similar results. A ratio was computed of the mean relative rate of extinction over the mean relative rate for the last two training session. Birds with ratios greater than 1.0 had higher mean relative rates in extinction than in training; that is, in extinction, response rate in the initial link was a larger proportion of total response rate than it was in training. For birds with a ratio greater than 1.0, extinction occurred more slowly in the initial link than in the terminal link relative to performance in the final training sessions.

As shown in Table 1, Birds 4, 5, and 6 all had ratios much higher than 1.0, and all other birds had ratios well below 1.0. The difference between the two groups of Ss was reliable (means $=1.52$ and .42; $t=5.24$, $\mathrm{df}=6, \mathrm{p}<.001$ ).

\section{Discussion}

The data indicated that in response chains extinction sometimes occurred more quickly in links closer to the goal, sometimes in links farther from the goal. With less training, links farther from the goal extinguished more quickly; with more training, links closer to the goal extinguished more quickly.

The effects of training interacted with another variable, however. Birds with extensive training showed faster extinction in links closer to the goal only when they were trained under satiation conditions. Under these conditions, they were given relatively large rewards and distributed practice. The variable, amount of reward or distribution of practice, has also proved to be significant in other experimental situations (Sperling, 1965).

\section{References}

FANTINO, E. Some data on the discriminative stimulus hypothesis of secondary reinforcement. Psychol Rec., 1965, 15, 409-415.

FERSTER, C. B., \& SKINNER, B. F. Schedules of reinforcement. New York: Appleton-Century-Crofts, 1957.

FISCHER, K. W., \& FANTINO, E. The effects of satiation upon performance in a behavior chain. In preparation.

LASHLEY, K. S. The problem of serial order in behavior. In L. A. Jeffress (Ed.), Cerebral mechanisms in behavior. New York: Wiley, 1951. Pp. 112-136.

NAPALKOV, A. V. Chains of motor conditioned reactions in pigeons. Pavl. J. high. new. Activ., 1959, 9, 539-545.

REESE, E. P. Experiments in operant behavior. New York: AppletonCentury-Crofts, 1964.

SPERLING, S. E. Reversal learning and resistance to extinction: A review of the rat literature. Psychol. Bull., 1965, 63, 281-297.

\section{Notes}

1. The author would like to thank Dr. M. Haith, J. Coppeto, and especially Dr. E. Fantino for help in this research, which was supported throughout by NSF Grant NSF-GB-3626 to Yale University, E. Fantino, Principal Investigator.

2. During training, response rates for all animals were clearly higher in the terminal link than in the initial link. 